\title{
PARA DIVERSIFICAR O ESTUDO DA CONEXÃO ELEITORAL NO BRASIL: UMA AGENDA DE PESQUISA
}

\section{Carolina de Paula ${ }^{1}$}

Resumo: O objetivo deste artigo é levantar brevemente a discussão teórica em torno da conexão eleitoral no Brasil e propor uma agenda de pesquisa sobre uma questão raramente explorada pelos cientistas políticos brasileiros e brasilianistas: a relação do representante com as bases eleitorais ao longo do mandato. Inicialmente o artigo discute o conceito de representação política no que tange ao sistema político. Em seguida analisa-se criticamente a literatura que envolve as características institucionais do poder Legislativo. Por fim apresenta-se uma agenda de pesquisa que visa realizar uma experimentação metodológica ao analisar a relação entre deputados federais e bases eleitorais na $54^{\mathrm{a}}$ Legislatura da Câmara dos Deputados (2011-2014).

Palavras-chave: poder Legislativo; representação política; conexão eleitoral.

Resumen: Este artículo brevemente elevar la discusión teórica en torno a la conexión electoral en Brasil y proponer una agenda de investigación sobre un tema raramente explorado por los científicos políticos: la relación de representantes a sus electores sobre el mandato. Inicialmente lo artículo se describe el concepto de representación política en lo que respecta al sistema político. A continuación, se analizan críticamente la literatura participación de las características institucionales del Poder Legislativo Finalmente, presentamos un programa de investigación que apunta a una metodología experimental para analizar la relación entre representantes federales y electorales en la $54{ }^{\text {a }}$ Asamblea Legislativa de la Cámara de Miémbros(2011-2014).

Palabras-clave: poder Legislativo; representación política; conexión electoral.

Abstract: This paper briefly raise the theoretical discussion around the electoral connection in Brazil and to propose a research agenda on an issue rarely explored by political scientists: the relationship of representative to their constituencies over the mandate. Initially the article discusses the concept of political representation in regard to the political system. Then we analyze critically the literature involving the institutional features of the legislative branch. Finally we present a research agenda that aims at an experimental methodology to analyze the relationship between federal representatives and constituencies in the 54th Legislature of the Chamber of Deputies (2011-2014).

Key-words: Legislative power; political representation; electoral connection.

\footnotetext{
${ }^{1}$ Doutoranda em Ciência Política no IUPERJ, bolsista CNPq.
} 


\section{INTRODUÇÃO}

Os estudos sobre as instituições representativas no Brasil, nas décadas posteriores à promulgação da Constituição de 1988, desenvolveram-se sustentados por evidências empíricas relativas a diversas temáticas que engendram o sistema político brasileiro. Nesses últimos vinte anos as pesquisas acadêmicas preocuparam-se com múltiplas temáticas, atenção especial foi destinada aos aspectos endógenos do Congresso Nacional - poderes de agenda do governo, organização interna do Legislativo, a relação Executivo-Legislativo (FIGUEIREDO E LIMONGI, 1999; AMORIM NETO E SANTOS, 2001; SANTOS, 2003; PEREIRA, POWER E RENNÓ, 2007) -; a migração partidária (MELO, 2004); aos efeitos do sistema eleitoral sobre o sistema partidário (SAMUELS, 1999; AMES, 2003; NICOLAU, 2007) ; entre outras questões referentes ao sistema presidencialista e federativo que aqui vigoram.

É notório que o entendimento do poder Legislativo recebeu centralidade na década de 90, certamente sob influência da teoria norte-americana sobre o Congresso e da perspectiva neoinstitucional ${ }^{2}$. As discussões dos pesquisadores que mensuraram o comportamento parlamentar - através da observação do comportamento dos legisladores nas votações nominais, por exemplo - esteve majoritariamente orientada por aspectos referentes ao processo decisório.

O objetivo deste artigo é apresentar brevemente a discussão teórica em torno da conexão eleitoral no Brasil e propor uma agenda de pesquisa sobre uma questão raramente explorada pelos cientistas políticos brasileiros e brasilianistas: a relação do representante com as bases eleitorais ao longo do mandato.

Sabe-se que o tema da conexão eleitoral esteve na agenda de pesquisa da Ciência Política internacional e brasileira. Contudo, o debate sobre os possíveis efeitos da arena eleitoral sob a legislativa tende a negligenciar a observação empírica do vínculo entre os parlamentares e suas bases nos interstícios eleitorais. A utilização de dados sobre a distribuição espacial dos votos dos representantes permitiu aos estudiosos captar parte importante da existência da conexão eleitoral no Brasil. Porém, ainda falta avançar no detalhamento da multiplicidade dessa vinculação representanterepresentado, tendo em vista que os estilos de carreira e atuação parlamentar podem apresentar contornos variados quando se observa o conjunto de parlamentares que exercem mandato eletivo na Câmara dos Deputados.

Os métodos de pesquisa dos poucos trabalhos que se preocuparam em mensurar o vínculo dos representantes com suas bases eleitorais agregaram procedimentos relativos a dois campos que os deputados estão inseridos: (1) no

\footnotetext{
2 Para um "estado da arte" sobre os estudos legislativos consultar (INÁCIO E RENNÓ, 2009).
} 
momento eleitoral: basicamente realizaram análises da distribuição espacial dos votos (CARVALHO, 2003; BORGES, 2005); (2) no âmbito interno do Legislativo: aspectos atitudinais dos representantes, captados via surveys ou entrevistas em profundidade (CARVALHO, 2003; LEAL, 2005; BORGES, 2005; VEIGA et al., 2008), e aspectos comportamentais, através da análise da produção legislativa dos mesmos (BORGES, 2005; VEIGA et al., 2008). Nota-se que para além das percepções dos próprios entrevistados, em nenhuma das pesquisas explicitou-se empiricamente o vínculo do parlamentar no que toca às suas próprias bases durante o exercício do mandato, faltam estudos que contemplem concomitantemente o padrão geográfico dos votos na Câmara dos Deputados e o comportamento parlamentar no dia-a-dia da representação política.

Além desta introdução o artigo contemplará três seções. A primeira delas aborda a discussão envolvendo o conceito de representação política no que tange ao sistema político. Na seção seguinte analisar-se-á a literatura acadêmica que abrange as características institucionais do poder Legislativo como tema de pesquisa, e mais especificamente àquela relativa ao comportamento do parlamentar. A última seção, de viés propositivo, terá como objetivo levantar uma agenda de pesquisa que consiga mensurar evidências empíricas para mais bem compreender a relação entre os representantes - no caso os deputados federais da $54^{\text {a }}$ Legislatura da Câmara dos Deputados (2011-2014) - e as bases eleitorais no Brasil.

\section{A REPRESENTAÇÃo POLÍTICA E O SISTEMA POLÍTICO}

Os pesquisadores interessados na análise das características do sistema político parecem, em geral, concordar que o primeiro passo é atentar para o termo da representação política. Em "Instituições Políticas Democráticas - o segredo da legitimidade", Lima Jr. (1997) apresenta o debate envolvendo a natureza e forma da representação entre os pensadores e filósofos políticos ${ }^{3}$ desde o final do século XVIII até o ano em que o texto foi publicado. Além da clareza sintética do autor ao abordar diversos conceitos e obras clássicas da teoria política, o texto ganha relevância ao ressaltar um ponto que passa muitas vezes despercebido nas pesquisas sobre engenharia institucional, seriam as conseqüências das escolhas institucionais para a dimensão qualitativa da democracia ${ }^{4}$. Referente às variadas facetas do mandato parlamentar, o autor evidencia que a discussão conceitual controversa sobre a representação ocupa grande espaço no debate sobre as origens do parlamento,

\footnotetext{
3 Thomas Hobbes, John Locke, Jean-Jacques Rousseau, Edmund Burke, Jonh Stuart Mill, José de Alencar. 4Esse ponto também é destacado na obra de LIJPHART, A. 2003. Modelos de democracia: desempenho e padrões de governo em 36 países. Rio de Janeiro: Civilização Brasileira.
} 
inclusive sobre a própria natureza do mandato e da relação representanterepresentado.

Vale expor os argumentos de Hanna Pitkin (1972) em "O conceito de representação", primeiro por sugerirem elucubrações em torno da representação, segundo porque são recorrentes na justificativa conceitual-normativa dos trabalhos empíricos contemporâneos sobre instituições. Ao demonstrar que a construção da idéia da representação enquanto um direito constitucional é relativamente recente - século XIX - "a falta de consenso sob um ângulo filosófico levanta problemas de como selecionar os representantes certos, ou como controlar os selecionados de modo que eles respondam efetivamente às necessidades e interesses das pessoas" 5 . Não cabe aqui apresentar o embate que a autora promove entre as concepções rivais hobbesianas e rousseaunianas, mas observar o cruzamento em que faz sobre o papel do representante e os tipos de representação. De acordo com Kinzo $(1980)^{6}$ o esquema de Pitkin trabalha com três conotações ${ }^{7}$, são elas, (a) conotação de autoridade; (b) conotação descritiva; (c) conotação que define a representação pelo ângulo da atividade do representante. A primeira agrega a visão weberiana de "dominação", sendo os mecanismos eleitorais a forma de concessão para autoridade dos eleitos. Já a segunda conotação, também conhecida como representação por espelho, intenciona a maior semelhança e correspondência entre o perfil do corpo representativo e dos representados. Por fim, a conotação da representação como atividade - certamente a de maior relevo na discussão atual - pode ser subdividida em duas questões: $\left(1^{\circ}\right)$ procura observar como de fato se dá a atividade representativa, engloba a controvérsia entre livre mandato ou representação independente $\mathrm{X}$ mandato imperativo ou representação mandatária, delegada; ( $\left.2^{\circ}\right)$ a questão que diz respeito sobre a natureza dos interesses e/ou desejos que orientariam a atividade do representante, isto é, como estes norteiam o ato de representar.

Em torno deste debate sobre a natureza da representação política e sua "implantação" na sociedade é possível destacar as considerações de Sartori (1962). Em “A Teoria da Representação no Estado Representativo Moderno" o autor aborda, na primeira parte do livro, temas envolvendo o problema jurídico-constitucional, e, na segunda parte, realiza a análise política e sociológica dos sistemas representativos. Na parte inicial, de veio jurídico da obra, Sartori argumenta que a representação política separa-se de sua matriz privatística na Constituição francesa de 1791, sendo o

5PITKIN, H. [1972]. 1983. O Conceito de Representação. In: CARDOSO, F.; MARTINS, C. Política e Sociedade. $2^{\mathrm{a}}$ ed. São Paulo: Editora Nacional. (p. 12)

${ }^{6} \mathrm{KINZO}$, M. 1980. Representação Política e Sistema Eleitoral no Brasil. São Paulo: Símbolo.

7(DESPOSATO, S. 2007) classifica os conceitos de Pitkin de forma diferente, seria a (1) representação substantiva; (2) representação simbólica; (3) representação descritiva; (4) representação formalista. Tratase apenas de uma diferença na apresentação do conceito, já que o conteúdo é o mesmo que o levantado por Kinzo. 
nascimento das modernas instituições representativas estabelecidas quando se admite que os deputados não deveriam representar apenas seus eleitores, mas sim toda a nação. A principal contribuição do autor italiano encontra-se na segunda parte do livro, pois Sartori incorpora à discussão o aparecimento dos partidos políticos, complexificando ainda mais a teoria da representação,

"deve-se considerar que, na relação entre eleitores- eleitos, se inserem - e com vastos reflexos - os partidos políticos. E a intervenção dos partidos modernos de organização complica o quadro, inserindo nele pertencimentos adquiridos e múltiplos" (SARTORI, 1962. p. 124).

Sartori ao incluir na discussão a variável partidos políticos amplia o quadro teórico, até então dualista, "representante-representado", numa tríade, "representante partidos políticos- representado". Um desdobramento desta inclusão será seu enfoque posterior na análise dos sistemas eleitorais, já que estes produziriam, a seu ver, um duplo efeito, primeiro nos eleitores, condicionando e influindo em sua escolha, segundo, em todo o sistema, seja em relação ao número e ao tipo de partidos, inclusive no que diz respeito às características institucionais do Estado representativo.

Dentro deste panorama, um diálogo com os argumentos de Sartori pode ser criado ao agregar a discussão promovida por Manin (1995) no texto "As Metamorfoses do Governo Representativo". O título do texto apresenta o argumento-chave, já que o autor preocupa-se em compreender a transição de modelos $^{8}$ ocorrida no final do século XIX e início do século XX entre a democracia de partidos para a de público. Apesar de ressalvar o mérito do autor em desmistificar uma "crise generalizada" da democracia, e também reconhecer a elegância do modelo, os apontamentos de Manin parecem sugerir uma excessiva expectativa na prática deliberativa do parlamento moderno gerar automaticamente a "boa" representatividade9. As visões de Sartori e de Manin servem de ilustração para observar que o grau das expectativas sobre os contornos da representação política, especialmente no que diz respeito aos partidos políticos, revelaria indiretamente as funções normativas - se governativa ou consultiva - que o parlamento teria para cada autor envolvido nesse debate, ou seja, a discussão está longe de galgar o consenso.

Se o objetivo instrumental final da representação política é constituir um corpo de representantes, independente se terá um caráter governamental ou

\footnotetext{
8 Resumindo rapidamente os argumentos de Manin: este trabalha com uma tipologia de formas de representação que seria observada numa sucessão linear histórica ("democracia parlamentar", os governantes são escolhidos por seus atributos pessoais e agem de acordo com sua consciência $\rightarrow$ "democracia de partido", os governantes são preparados pelos partidos e agem fielmente afinados com um sentimento de pertencimento ao grupo $\rightarrow$ "democracia de público", o governo é personalizado e fatores exógenos como as pesquisas de opinião aparecem enquanto motivadoras das escolhas eleitorais).

9 Talvez seja possível supor que a concepção de Manin da interferência, em certa medida, prejudicial do papel mediador dos partidos na relação representante-representado decorre dessa elevada expectativa.
} 
consultivo, é plausível o interesse dos pesquisadores na compreensão dos mecanismos que delineia esse grupo de indivíduos. Uma definição conceitual sintética sobre sistemas eleitorais foi elaborada por Tavares (1994),

\begin{abstract}
"Sistemas eleitorais são construtos técnico- institucional -legais instrumentalmente subordinados, de um lado, à realização de uma concepção particular da representação política e, de outro, à consecução de propósitos estratégicos específicos, concernentes ao sistema partidário, à competição partidária pela representação parlamentar e pelo governo, à constituição, ao funcionamento e alternância dos governos, ao consenso público e à integração do sistema político" (p. 13).
\end{abstract}

Embora a citação seja clara, vale apontar o quanto a discussão normativa sobre o "que deve ser a boa representação" e a dimensão das criações institucionais para atingi-la, os sistemas eleitorais, guarda proximidade. A coletânea organizada por Lima Jr. (1991), contemplando ensaios teóricos e empíricos sobre o formato e efeitos dos aspectos que constituem o sistema eleitoral brasileiro, sugere a própria amplitude da democracia do país enquanto dependente de mecanismos e regras que balizam um momento essencial da representação política, as eleições. É preciso destacar que o estudo da representação política não se restringe unicamente ao momento eleitoral, atentar para os aspectos relacionados ao exercício do mandato permitiria mais bem mensurar os contornos da representação política em um determinado sistema político, dessa forma é que os estudos sobre o comportamento legislativo ganham importância.

\title{
O PODER LEGISLATIVO E A CONEXÃO ELEITORAL
}

Conforme exposto na apresentação do texto, o viés majoritário das pesquisas sobre as instituições brasileiras no pós-88 receberam forte influência do paradigma neoinstitucional. Pesquisas que procuraram compreender as características e o funcionamento do poder Legislativo no Brasil, especialmente desde o início da década de 1990, muito contribuíram para a compressão deste importante locus da representação política. É necessário mencionar, logo de saída, o alto grau de divergência quanto às conclusões entre os pesquisadores da temática. Entretanto, salienta-se que tal divergência pode ser vista sob uma ótica positiva, pois é indicativa do considerável esforço dos analistas em pensarem o Legislativo brasileiro em sua complexidade. No que diz respeito às convergências das análises relativas ao Congresso 
Nacional, é notória a influência das teorias positivas sobre o Legislativo norteamericano ${ }^{10}$ pelos pesquisadores, tanto brasileiros quanto brasilianistas.

Em linhas gerais, os três modelos, derivados das teorias positivas seriam: (a) o “modelo distributivista", tendo em Mayhew (1974) a argumentação sobre a conexão eleitoral enquanto exponencial. Pode-se resumir que a estrutura das comissões e subcomissões do Congresso dos EUA serviria para facilitar a conexão dos congressistas com seus eleitores e para maximizar os ganhos de troca, já que o objetivo final dos parlamentares seria sempre a reeleição; (b) o "modelo informacional", derivado com o primado da decisão majoritária e o postulado da incerteza. Neste modelo as comissões, e os demais expedientes legislativos, potencializariam ou subtrairiam o poder individual do parlamentar de formular políticas para seu próprio interesse eleitoral. Krehbiel (1991) no estudo Information and Legislative Organization levanta duas premissas das comissões, a primeira seria reduzir as incertezas das decisões legislativas e seus efeitos através da deliberação parlamentar; a segunda seria a democratização das informações para se aproximar da preferência do parlamentar mediano; (c) o "modelo partidário". De acordo com Cox e McCubbins (1993) os partidos formariam uma espécie de cartel legislativo, sendo o controle da agenda do legislativo realizado pelo partido majoritário. Aqui, o líder daria prioridade de agenda aos projetos que guardassem relação com sua posição.

Os estudos realizados tendo o Legislativo nacional brasileiro enquanto laboratório buscaram inseri-lo nesses modelos. Na procura de entendimento sobre o processo decisório no período posterior a elaboração da Constituição de 1988, e, ainda que parcialmente, guiados pelo modelo partidário, Figueiredo e Limongi (1999) afirmaram através de amplo levantamento de dados e análises estatísticas que o sistema político brasileiro possuía condições de governabilidade e até mesmo previsibilidade nos resultados das decisões. Argumentaram que o sistema político brasileiro não geraria as condições motivacionais e nem mesmo as institucionais para que políticos projetassem suas carreiras políticas exclusivamente em vínculos pessoais e apartidários com os eleitores e com o Executivo. Os autores refutaram a idéia de que as relações na arena decisória apresentariam uma forma de barganha entre um Executivo carente de apoio no Congresso e legisladores interessados em políticas públicas para o atendimento dos interesses particulares e imediatos de suas clientelas eleitorais.

10 Ainda que aglutinem um amplo leque de vieses, é possível chamar, genericamente, "teorias positivas sobre o legislativo norte-americano" as explicações baseadas em constatações empíricas sob o arsenal institucional do Congresso norte americano e no comportamento individual dos congressistas. O foco principal dessas teorias seriam as comissões. A definição mais completa encontra-se em SHEPSLE, K.; WEINGAST, B. 1994. Positive theories of congressional institutions. Legislative Studies Quartely. XIX. May. p. 149-179. 
A utilização metodológica de variáveis externas ao ambiente do processo decisório é feita com menor freqüência pelos pesquisadores quando comparadas às variáveis internas. Nesta visão, a perspectiva distributivista - isto é, a premissa de que a vontade de se reeleger e a pressão do eleitorado influenciam de maneira determinante a atitude e as ações dos deputados nos processos legislativos - é anexada. Autores inseridos nessa abordagem afirmam que a liberação das verbas orçamentárias relativas às emendas individuais pode ser vista como importante moeda de troca nas negociações entre o Executivo e o Legislativo. Argumentam que o Executivo no Brasil seria frágil e chantageado por legisladores oportunistas (AMES, 2003). Sobre o sistema eleitoral e partidário, Ames (2003) critica o efeito negativo - personalista e paroquial que este causaria no sistema político brasileiro. As regras do sistema eleitoral gerariam um comportamento individual dos parlamentares, fazendo com que estes buscassem constantemente benefícios localizados para suas bases de votação, ocasionando assim o enfraquecimento do Congresso enquanto órgão decisório. Outra conseqüência da suposta permissividade do sistema eleitoral seriam as dificuldades para o presidente cumprir sua agenda de governo.

Faz-se necessário observar que tentativas recentes de compreender a dinâmica do Legislativo no Brasil posicionam-se a favor de uma explicação mais abrangente. Ou seja, parte dos pesquisadores reconhece a debilidade de uma dicotomia entre a teoria partidária e distributivista. Pereira e Mueller (2002) garantem haver necessidade de reconhecimento de ambas as perspectivas, já que no Brasil existiriam incentivos ao individualismo (arena eleitoral), contudo as regras da arena legislativa restringiriam o comportamento personalista, impulsionando um comportamento partidário e coletivo.

Atualmente, grande parte dos pesquisadores reconhece a impertinência na adoção integral de cada uma das teorias positivas norte-americanas, ou, então, procuram adotá-las justapostas, já que análises comparativas razoáveis precisam considerar as especificidades de cada unidade a ser comparada. Na obra "E no início eram as bases" Carvalho (2003) demonstra uma postura ponderada, dotada de cautela, ao analisar a conexão eleitoral e a geografia do voto no Brasil. Carvalho desenvolve uma pesquisa sobre a conexão eleitoral no Brasil entre 1994-1998. A partir da geografia do voto o autor controla a variável Concentração/Dispersão. Para ele haveria impacto das diferentes origens eleitorais dos congressistas sobre o comportamento legislativo. Carvalho corrobora a afirmação de Ames (2003) de que haveria no Brasil uma disputa pelo espaço físico eleitoral dos municípios. Na visão de Ames os parlamentares brasileiros teriam grande incentivo para agirem de maneira localista devido à realidade socioeconômica do eleitorado e também devido à distribuição espacial dos votos, muito concentrada e dominante. Ames (2003) desenvolve uma tipologia de "distritos" 
informais: (i) concentrados-dominantes; (ii) concentrados-compartilhados; (iii) dispersos-dominantes; (iv) dispersos-compartilhados. Carvalho (2003) por sua vez apresenta a hipótese de que deputados com padrão geográfico de distribuição de votos não-dominante se orientarão pelo universalismo legislativo, já a lógica do paroquialismo, preocupado estritamente com os interesses das bases, seria tão somente propriedade dos deputados com votação dominante. O procedimento metodológico da pesquisa de Carvalho é a aplicação de um survey com 280 deputados federais contemplando mais de cem questões relacionadas às atitudes dos mesmos. As conclusões do autor sugerem forte personalização dos mandatos representativos, desvalorização dos partidos como bens coletivos em sua dimensão eleitoral e uma predisposição de se votar em interesses particulares quando estes se opõem aos interesses partidários. Vale destacar que o cruzamento da distribuição dos votos com variáveis comportamentais dos parlamentares, isso é, o que fazem na Câmara, serviu para ponderar tanto o argumento próximo ao modelo distributivista quanto ao modelo partidário para o Legislativo brasileiro, já que foram encontrados deputados agindo em consonância com os dois modelos vinculados às teorias norte-americanas.

Outros estudos também analisaram a conexão eleitoral na esfera subnacional. Borges (2005) apresenta um estudo de caso sobre a atuação parlamentar e as relações dos deputados estaduais com suas bases na $14^{\mathrm{a}}$ Legislatura (1999-2002) da Assembléia Legislativa do Maranhão. Com intenções de mensurar as percepções e práticas dos deputados a autora realizou um survey com entrevistas semi-dirigidas e presenciais envolvendo 31 representantes, além de agregar dados sobre a produção legislativa dos mesmos em consonância à distribuição espacial dos votos. Veiga et al. (2008) realizaram entrevistas em profundidade com 40 deputados estaduais da $15^{\text {a }}$ Legislatura da Assembléia Legislativa do Paraná, também intencionaram analisar as percepções dos legisladores estaduais sobre o próprio trabalho no Legislativo estadual. Assim como Leal (2005) e Carvalho (2003), Borges (2005) e Veiga et al. (2008) encontraram uma articulação entre a esfera legislativa e a esfera eleitoral, ou seja, as características personalistas do sistema representativo brasileiro - oriundas em certa medida do sistema eleitoral de lista aberta ${ }^{11}$ e da possibilidade de coligações partidárias ${ }^{12}$ - não se limitaram ao momento eleitoral. Ainda que as regras endógenas da Câmara dos Deputados (e de algumas Casas Legislativas Estaduais) estruturem e centralizem o processo decisório via partidos políticos ${ }^{13}$, parte dos parlamentares brasileiros mantém

\footnotetext{
${ }^{11}$ Carey e Shugart (1995).

12 Nicolau (2007) afirma que apesar das reduzidas pesquisas sobre os efeitos da lista aberta sobre os partidos no Brasil existiriam evidências de que as campanhas são principalmente centradas no candidato. $\mathrm{O}$ autor adverte que tais evidências não significam que alguns partidos não utilizem estratégias mais coletivas, por exemplo, práticas de campanha realizadas pelo PT e PC doB.

13 Figueiredo e Limongi (1999); Santos (2003).
} 
fortes ligações com suas bases. Vale destacar que essas conclusões não significam afirmar que o paroquialismo é a única atividade e forma de atuação dos legisladores, tal como Ames (2003) havia sugerido. Ações parlamentares mais universalistas, como o position taking (tomada de posição), são possíveis e notadas na Câmara dos Deputados e Assembléias Legislativas estaduais.

É pertinente apresentar os estudos desenvolvidos no âmbito da antropologia da política que também se preocuparam em mais bem compreender a relação representante e bases eleitorais no Brasil. Foi na década de 1990 que os antropólogos brasileiros passaram a dar maior atenção aos assuntos da política, tanto no desenvolvimento de etnografias no espaço urbano quanto no meio rural14. Utilizando, principalmente, o método etnográfico - alicerçado pela observação participante e pelas entrevistas em profundidade - diversas práticas, até então pouco relatadas em seu nível "micro" pela ciência política e pela sociologia, foram temas de estudos: comícios eleitorais (PALMEIRA E HERÉDIA, 1995); organização de campanhas eleitorais, trajetórias de parlamentares e redes sociais (KUSCHNIR 2000a; 200ob); aspectos do dia-a-dia dos deputados no Congresso (BEZERRA, 1999); entre outros. Vale ressaltar que a descrição minuciosa de práticas políticas sem pré-noções, como o clientelismo, por exemplo, consiste num dos principais paradigmas da antropologia da política, ou seja, busca-se em última instância eliminar qualquer viés de normatividade aos fenômenos analisados, sendo o ponto de vista do "nativo" o principal elemento a conferir legitimidade às pesquisas.

Em "O Cotidiano da Política" Kuschnir (2000a) analisa os contornos da mesma através do método etnográfico em um bairro carioca. Ao observar como se processa a política, em seus diversos momentos - eleitorais ou não - estabelece a idéia central de seus argumentos: o parlamentar enquanto um mediador de alianças $e$ intérprete cultural. Inserida na rotina de uma família de políticos ${ }^{15}$, entre agosto de 1995 e janeiro de 1997, a pesquisadora levantou diversos aspectos concretos da atividade política, desde a organização da campanha até a relação, após a vitória nas urnas, da família Silveira com a população e os órgãos públicos.

Em trabalho anterior, Kuschnir (200ob) descreve o argumento acima mencionado e classifica os vereadores da Câmara Municipal do Rio de Janeiro em "assistencialistas" e "ideológicos". Em linhas gerias, os primeiros seriam dotados de uma postura de benfeitores e patronos para os eleitores que, individualmente, os procuram; e os segundos estariam mais interessados em estimular o contato entre toda

\footnotetext{
${ }^{14}$ Kuschnir argumenta que a institucionalização mais importante concentra-se no Núcleo de Antropologia da Política (NuAP) com sede no Museu Nacional, este agrega também grupos de pesquisa de universidade federais do Ceará, Brasília, Rio Grande do Sul, entre outras.

15 Chamados ficticiamente de família Silveira.
} 
a comunidade e o órgão municipal responsável pelo problema dos cidadãos. Contudo, a autora adverte que a conexão do parlamentar com seus eleitores - seja de forma individual ou comunitária - é permanente, e uma característica genuína do mandato político.

Através de uma etnografia realizada no Congresso Nacional entre maio e julho de 1996, Bezerra (1999) elucida aspectos sobre o comportamento dos representantes no contexto de aprovação do orçamento. Ao longo do trabalho o autor examina o interesse - no sentido do que levaria as pessoas a fazerem o que fazem - dos diversos agentes sociais envolvidos no processo de liberação de recursos federais para suas bases eleitorais. Conclui que o interesse não é apenas material, já que a personalização das relações políticas e a apresentação das trocas políticas nos termos de desinteresse constituiriam, a seu ver, parte da racionalidade autônoma do clientelismo político.

Os trabalhos desenvolvidos no âmbito da antropologia da política podem se aproximar ao debate sobre a conexão eleitoral realizado pela Ciência Política, mas sem dúvida é preciso tecer algumas considerações. É evidente que a Antropologia e a Ciência Política possuem especificidades epistemológicas e metodológicas. Palmeira e Goldman (1996) em “Antropologia, Voto e Representação Política” procuraram demarcar as distinções entre as disciplinas em relação aos estudos eleitorais. Afirmam os autores, no capítulo de apresentação da coletânea organizada por ambos, que os trabalhos sobre eleições desenvolvidos pela Ciência Política teriam uma visão "internalista" dos fenômenos, concentrada na valorização dos partidos políticos como centrais (PALMEIRA E GOLDMAN, 1996:06-07) e por diversas vezes apresentando conclusões negativas da dinâmica eleitoral e da falta de racionalidade do eleitor no Brasil, essas conclusões - errôneas para eles - seriam causadas pelo isolamento das eleições como objeto de pesquisa, sendo a análise antropológica do voto interessada em processos microssociológicos ou micropolíticos contextualizados.

Mais recentemente Kuschnir (2007:63) argumentou que a Antropologia, por sua fidelidade ao particular e necessidade de produzir generalizações, em muito ganharia ao dialogar com as demais disciplinas, tais como a História, Ciência Política, Sociologia, Lingüística e Comunicação. Se a Antropologia ganha ao estabelecer aproximações com as demais disciplinas, estas também serão beneficiadas ao se utilizarem de elementos da Antropologia para ampliar seu próprio arsenal explicativo.

Mas como realizar na prática uma aproximação de tal envergadura? Como estudar instituições políticas em seus elementos "macro" e "micro" ao mesmo tempo? É certo que a Ciência Política preocupa-se em análises que considerem o sistema político em questão, talvez seja esta a principal diferença em relação à antropologia da política. A última seção do artigo busca elaborar, ainda que de maneira embrionária, uma 
agenda de pesquisa para mais bem mensurar a temática da conexão eleitoral para além dos resultados intrínsecos ao processo decisório e também àqueles estritamente ligados à arena eleitoral.

\section{UMA AGENDA DE PESQUISA PARA DIVERSIFICAR O ESTUDO DA CONEXÃO ELEITORAL NO BRASIL}

Os dois conjuntos de trabalhos empíricos levantados ${ }^{16}$ na seção anterior possuem lacunas que poderão ser minimizadas caso haja um diálogo entre eles. Na compreensão do relacionamento entre representantes e bases eleitorais uma tentativa bem sucedida na adoção de uma perspectiva empírica e metodológica mais plural foi realizada por Fenno Jr.(1990) no contexto dos EUA. Em "Watching Politicians - essays on participant observation" o autor apresenta cinco artigos escritos ao longo de vários anos de pesquisa acadêmica, inclusive dois textos de cunho metodológico, que permitem vislumbrar procedimentos - como a etnografia e a observação participante, por exemplo - bastante viáveis na análise do comportamento parlamentar, porém raramente utilizados nos estudos da Ciência Política brasileira.

Para pesquisar a conexão eleitoral a proposta ${ }^{17}$ é analisar a relação entre os deputados federais da 54 ${ }^{\mathrm{a}}$ Legislatura da Câmara dos Deputados (2011-2014) com suas bases eleitorais. A pesquisa será segmentada em duas etapas. A primeira etapa, em consonância aos achados da literatura da temática, analisará a distribuição espacial dos votos dos 513 deputados federais. A hipótese é que os distintos padrões espaciais da votação gerem incentivos diferenciados no que tange ao comportamento legislativo. A unidade de análise será cada deputado federal, dessa forma, a proposta é mensurar o perfil da Câmara dos Deputados seguindo o mesmo procedimento de Carvalho (2003:95-96): aplicar à votação dos deputados eleitos o índice de fragmentação de Rae, o índice irá sugerir o número de municípios em que os deputados eleitos foram votados de forma efetiva. A partir disso será possível estabelecer faixas de concentração e dispersão do voto que permitam mensurar os padrões de concentração e dispersão do voto por região/estado do país bem como no que concerne às siglas partidárias.

Inclui-se nessa primeira etapa o vetor de análise introduzida por Ames (2003) quanto à geografia eleitoral, chamado na literatura de dominância, ou seja, a penetração vertical dos votos dos deputados. A fórmula utilizada operacionaliza o

\footnotetext{
16 "Conjunto" se refere às pesquisas aqui brevemente sistematizadas, no âmbito da Ciência Política (CARVALHO, 2003; LEAL, 2005; BORGES, 2005; VEIGA et al, 2008) e da Antropologia (KUSCHNIR 2000a; 200ob; BEZERRA, 1999).

17 Esta seção discute o projeto de pesquisa de doutorado da autora, intitulada provisoriamente "Representantes e bases eleitorais na 54 a Legislatura da Câmara dos Deputados (2011-2014)". Salienta-se que as considerações são de caráter exploratório, longe de serem conclusivas.
} 
número de votos recebidos pelo deputado na cidade considerando no cálculo o número total de votos válidos para deputado federal na cidade e o total de votos recebidos pelo deputado em todo o estado. A dominância permitirá identificar os padrões regionais da votação para $54^{\mathrm{a}}$ Legislatura da Câmara, tal como a concentração e a dispersão. Quanto às variáveis explicativas para o padrão de distribuição espacial dos votos intenciona-se criar dois grupos de variáveis independentes, (1) relativas ao estado do deputado: número de concorrentes no pleito; magnitude do distrito e do eleitorado; quantidade de municípios e (2) relativas ao perfil do deputado: carreira prévia e trajetória. Esses dados poderão ser obtidos no site do TSE e no Anuário Biográfico da Câmara dos Deputados.

Após o mapeamento da distribuição espacial dos votos a etapa seguinte da pesquisa desenhará uma amostra de deputados a partir dos quatro tipos de votação discutidos pela literatura para mais bem explorar a variável dependente da pesquisa: a relação dos deputados federais com suas bases ao longo do mandato. Destacou-se neste texto que os estudos da Ciência Política interessados na problemática - vale ressaltar que a literatura é escassa e a relação deputado-base eleitoral foi, na maioria dos casos, uma questão tangencial dos autores - utilizaram enquanto método de pesquisa a aplicação de surveys ou entrevistas em profundidade. O problema desses dois procedimentos é que as conclusões limitam-se à percepção do entrevistado, por isso, a proposta aqui é utilizar o método etnográfico. Assim como Fenno Jr. (1990) acredita-se na pertinência na análise das atividades dos parlamentares em seus próprios locais de votação durante o exercício do mandato. Esse procedimento elucidaria conhecer uma dimensão da conexão eleitoral ainda pouco explorada na Ciência Política nacional, afinal, de que maneira os deputados federais brasileiros organizam seu próprio mandato? Como são as suas redes nos municípios? Sabe-se que o contexto estadunidense em que Fenno Jr. (1990) pesquisou diz respeito a um sistema representativo de voto distrital, diferente do modelo proporcional brasileiro, contudo, a distribuição espacial dos votos parece um bom ponto de partida para identificar as bases eleitorais dos parlamentares. O recorte dessa segunda etapa da pesquisa levará em consideração não apenas o acompanhamento das atividades dos deputados junto às bases, mas também variáveis explicativas tradicionais nos estudos sobre o comportamento parlamentar, intrínsecas à atividade legiferante na Câmara dos Deputados: a) apresentação de projetos de lei; b) propostas de emendas orçamentárias; c) posicionamento nas votações nominais.

Neste momento ainda há muitas perguntas e nenhuma resposta. O objetivo do texto foi essencialmente sugerir um percurso metodológico dentro da ampla temática da conexão eleitoral. Sabe-se que os "estudos legislativos" consistem temas de pesquisa 
de considerável número de acadêmicos, contudo, certo grau de inovação na forma de captar evidências empíricas poderia matizar questões fundamentais que envolvem a importante discussão da representação política no país.

\section{REFERÊNCIAS}

AMES, B. Os Entraves da Democracia no Brasil. Rio de Janeiro: FGV, 2003.

AMORIM NETO, O. e SANTOS, F. A conexão presidencial: facções pró e antigoverno e disciplina partidária no Brasil. Dados Revista de Ciências Sociais. Rio de Janeiro, vol.44, $\mathrm{n}^{\mathrm{o}}$. 2, p. 291-321, 2001.

BEZERRA, M. Em nome das bases - política, favor e dependência pessoal. Rio de Janeiro: Relume Dumará, 1999.

BORGES, A. Conexão Eleitoral e Atuação Parlamentar - representantes e bases eleitorais no Maranhão. Tese de doutorado, Rio de janeiro, IUPERJ, 2005.

CARDOSO, F.; MARTINS, C. Política e Sociedade. $2^{\text {a }}$ ed. São Paulo: Editora Nacional, 1983.

CAREY, J. and SHUGART, M. Incentives to Cultivate a Personal Vote: A Rank Ordering of Electoral Formulas. Electoral Studies, vol. 14, n 4 . pp. 417-439, 1995.

CARVALHO, N. E no início eram as bases: geografia política do voto e comportamento legislativo no Brasil. Rio de Janeiro: Revan, 2003.

COX, G. and MCCUBINS, M. The Legislative Leviathan. Party Government in the House. Bekeley: University of California Press, 1993.

DESPOSATO, S. Reforma política brasileira: o que precisa ser consertado, o que não precisa e o que fazer. In. NICOLAU, J.; POWER, T. (org.) Instituiçõoes representativas no Brasil: balanço e reforma. Belo Horizonte: Editora UFMG, 2007.

FENNO Jr., R. Watching Politicians - essays on participant observation. Berkeley: University of Califórnia, 1990.

FIGUEIREDO, A. e LIMONGI, F. Executivo e Legislativo na Nova Ordem Constitucional. Rio de Janeiro: FGV, 1999.

INÁCIO, M. e RENNÓ, L. (org.) Legislativo Brasileiro em Perspectiva Comparada. Belo Horizonte: Editora UFMG, 2009.

KINZO, M. Representação Política e Sistema Eleitoral no Brasil. São Paulo: Símbolo, 1980.

KREHBIEL, K. Information and Legislative Organization. Ann Arbour: University of Michigan Press, 1991.

KUSCHNIR. K. O cotidiano da política. Rio de Janeiro: Zahar, 2000.

. Eleições e representação no Rio de Janeiro. Rio de Janeiro, RelumeDumará/NuAP. (Coleção Antropologia da Política), 2000. 
. Antropologia da Política. 1. ed. Rio de Janeiro: Jorge Zahar, 2007.

LEAL, P. O PT e o dilema da representação política: os deputados federais são representantes de quem? Rio de Janeiro: FGV, 2005.

LIJPHART, A. Modelos de democracia: desempenho e padrões de governo em 36 países. Rio de Janeiro: Civilização Brasileira, 2003.

LIMA Jr., O. (org.). Sistema eleitoral brasileiro: teoria e prática. Rio de Janeiro: Rio Fundo Ed., IUPERJ, 1991.

LIMA Jr., O. Instituições Políticas Democráticas: o segredo da legitimidade. Rio de Janeiro: Jorge Zahar Editor, 1997.

MANIN, B. As metamorfoses do governo representativo. Revista Brasileira de Ciências Sociais. n.29, ano10, ANPOCS, 1995.

MAYHEW, D. Congress: The Electoral Connection. New Haven, Yale University Press, 1974.

MELO, C. Retirando as cadeiras do lugar: migração partidária na Câmara dos Deputados, 1985-2002. Belo Horizonte: Editora UFMG, 2004.

NICOLAU, J; POWER, T. (org.) Instituições representativas no Brasil: balanço e reforma. Belo Horizonte: Editora UFMG, 2007.

NICOLAU, J. O sistema eleitoral de lista aberta no Brasil. In: NICOLAU, J.; POWER, T. (Org.) Instituições Representativas no Brasil: Balanço e Reforma. Belo Horizonte: UFMG, 2007.

PALMEIRA, M. e HEREDIA, B. Os comícios e a política de facções. Anuário Antropológico/94. Rio de Janeiro: Tempo Brasileiro, 1995.

PAlmeira, M. e GOLDMAN, M. (Org.) Antropologia, Voto e Representação Política. Rio de Janeiro, Contra Capa, 1996.

PEREIRA, C.; MUELLER, B. Comportamento Estratégico em Presidencialismo de Coalizão: as relações entre executivo e legislativo na elaboração do orçamento brasileiro. Dados Revista de Ciências Sociais, vol. 45, $\mathrm{n}^{\circ}$ 2, Rio de Janeiro. pp. 265-301, 2002.

PEREIRA, C.; POWER, T.; RENNÓ, L. Presidentes, poder de agenda e as conseqüências imprevistas da reforma das medidas provisórias. In: NICOLAU, J.; POWER, T. (Org.) Instituições Representativas no Brasil: Balanço e Reforma. Belo Horizonte: UFMG, 2007.

PITKIN, H. [1972]. O Conceito de Representação. In: CARDOSO, F.; MARTINS, C. Política e Sociedade. $2^{\text {a }}$ ed. São Paulo: Editora Nacional, 1983.

SAMUELS, D. Incentives to Cultivate a Party Vote in a Candidate-Centric Electoral System. Comparative Political Studies, v. 32, n.4, 1999.

SANTOS, F. O Poder Legislativo no Presidencialismo de Coalizão. Rio de Janeiro: IUPERJ, 2003. 
SARTORI, G. 1962. A Teoria da Representação no Estado Representativo Moderno. Revista Brasileira de Estudos Políticos. Belo Horizonte, 1962.

SHEPSLE, K.; WEINGAST, B. 1994. Positive theories of congressional institutions. Legislative Studies Quartely. XIX. May. pp. 149-179, 1994.

TAVARES, J. 1994. Sistemas eleitorais nas democracias contemporâneas: teoria, instituições, estratégia. Rio de Janeiro: Relume-Dumará, 1994.

VEIGA, L. et al. Conexão Eleitoral em uma Assembléia Legislativa: a atuação do parlamentar e atitude do eleitor". Paper apresentado no $6^{\circ}$ Encontro da ABCP, Campinas, 2008. 